\title{
COMUNICAÇÃO
}

\section{REDUÇÃO DA OXIDAÇÃO NA PROPAGAÇÃO IN VITRO DA BANANEIRA 'MAÇÃ ’}

\author{
Oxidation reduction of in vitro propagation of banana cv. Maçã plants \\ Mara Rubia Camolesi ${ }^{1}$, Erika Sayuri Kaihara ${ }^{2}$, Cibelle Garcia Saconi², \\ Ricardo Tadeu de Faria $^{3}$, Carmen Silvia Vieira Janeiro Neves ${ }^{3}$
}

\begin{abstract}
RESUMO
A técnica de cultivo in vitro de bananeira enfrenta o problema de oxidação dos ápices caulinares na fase de estabelecimento. Conduziu-se este trabalho, para avaliar a combinação de ácido cítrico e citrato de potássio, buscando reduzir a oxidação in vitro de bananeira 'Maçã'. Os ápices caulinares, medindo $15 \mathrm{~mm}$ de pseudocaule e $5 \mathrm{~mm}$ de rizoma, foram cultivados no meio MS, com metade da concentração dos macronutrientes. Os tratamentos foram organizados em esquema fatorial $2 \times 2 \times 2$ (com e sem pré-tratamento de antioxidantes por 90 minutos, com e sem a adição dos antioxidantes ao meio de cultivo e com e sem a transferência dos ápices caulinares; aos 15 dias, após a inoculação). Cada tratamento foi constituído por 15 ápices caulinares. Foram avaliados o grau de oxidação e o número de brotos na primeira e na segunda repicagem. O menor grau de oxidação foi obtido com o pré-tratamento dos ápices caulinares em $0,25 \mathrm{~g} \mathrm{~L}^{-1}$ de ácido cítrico e $0,75 \mathrm{~g} \mathrm{~L}^{-1}$ de citrato de potássio, sem a adição desses antioxidantes ao meio de cultivo e sem a necessidade de transferência dos ápices caulinares, aos 15 dias.
\end{abstract}

Termos para indexação: Musa, cultura de tecidos, micropropagação, fenol, estabelecimento.

\section{ABSTRACT}

The in vitro cultivation technique of banana plants faces the problem of oxidation of the stem apex in the establishment phase. The objective of this work was to evaluate the use of the combination of citric acid and potassium citrate, to reduce the in vitro oxidation of 'Maçã' banana plants. The explants, measuring $15 \mathrm{~mm}$ of pseudostem and $5 \mathrm{~mm}$ of rhizome, were established in the MS medium with half concentration of the macronutrients. The treatments were organized in factorial design $2 \times 2 \times 2$ (with and without pre-treatment of antioxidants for 90 minutes, with and without the addition of the antioxidants in the medium and with and without subculture to the 15 days after the inoculation). Each treatment was constituted by 15 stem apexes. The oxidation degree and the number of buds in the first and in the second re-culture were evaluated. The smallest oxidation degree was obtained with the pretreatment of the stem apexes in $0,25 \mathrm{~g} \mathrm{~L}^{-1}$ of citric acid plus $0,75 \mathrm{~g} \mathrm{~L}^{-1}$ of potassium citrate, without the addition of these antioxidants to the medium of cultivation and without subculture.

Index terms: Musa, tissue culture, micropropagation, phenol, establishment.

\section{(Recebido em 10 de março de 2006 e aprovado em 26 de março de 2007)}

A bananicultura brasileira enfrenta problemas fitossanitários como nematóides e pragas, especialmente a broca-do-rizoma, além de doenças como Moko, Mal-doPanamá. Todos esses fatores podem ser transmitidos pelo uso de mudas contaminadas, prejudicando o cultivo e causando prejuízos à bananicultura nacional (ZAFFARI et al., 1994).

Uma alternativa para obtenção de mudas com alta qualidade fitossanitária é a micropropagação. Porém, o estabelecimento dos ápices caulinares em condições assépticas, durante o processo de micropropagação, é uma das fases mais críticas, em função da contaminação por fungos e bactérias e pela oxidação, caracterizada pelo escurecimento do ápice caulinar ou até mesmo do meio de cultivo (GRATTAPAGLIA \& MACHADO, 1998). A oxidação é causada pela reação das polifenoxidases sobre compostos fenólicos e, no caso da bananeira, pode levar os ápices caulinares à morte, nas fases iniciais de desenvolvimento ou prejudicar o desempenho da fase de multiplicação (SOUZA et al., 2000; VUYLSTEKE \& LANGHE, 1985), trazendo prejuízos significativos em um laboratório comercial.

Registros na literatura relatam diferenças entre as cultivares em relação à intensidade de oxidação, o que pode ser atribuído às características intrínsecas do grupo genômico AAB (ANGARITA \& PEREA, 1991, citados por SOUZA et al., 1999).

\footnotetext{
'Bióloga, Doutoranda em Agronomia - Departamento de Biotecnologia Vegetal -Rua Doutor Geraldo Nogueira Leite, 1735 - $19804-050$ - Assis, SP _ mrcamol@femanet.com.br

²Bióloga - Departamento de Biotecnologia Vegeta - Rua Doutor Geraldo Nogueira Leite, 1735 - 19804-050 - Assis, SP - erikasayuri_k@yahoo.com.br, belikka@ig.com.br

${ }^{3}$ Engenheiros Agrônomos, Doutores, Professores - Departamento de Agronomia - Universidade Estadual de Londrina/UEL - Cx.P. 6001 - 86051-990 Londrina, PR - faria@uel.br; csvjneve@uel.br - Bolsista CNPq
} 
A utilização de diversos antioxidantes é relatada na literatura, tanto para bananeira como para outras culturas, como alternativa para a diminuição do processo de oxidação. Grattapaglia \& Machado (1998) recomendam a adição ao meio de cultivo ou o pré-tratamento, em solução de antioxidantes, para diminuição da oxidação.

A combinação de ácido cítrico e citrato de potássio foi testada na micropropagação de Symonanthus bancroftii (F. Muell.) L. Haegi (Solanaceae) (PANAIA et al., 2000) e Conostephium pendulum Benth. (Ericaceae) (ANTHONY et al., 2004), mas não foram encontrados relatos do uso dessas substâncias para bananeira.

O objetivo deste trabalho foi avaliar a utilização da combinação dos antioxidantes ácido cítrico e citrato de potássio; no controle da oxidação in vitro de ápices caulinares de bananeira 'Maçã'.

Foram utilizados 120 ápices caulinares de mudas do tipo chifrinho da cultivar Maçã (Musa spp. AAB), colhidas no município de Palmital - SP com latitude $22^{\circ} 46^{\prime} 60 \mathrm{~S}$, longitude $50^{\circ} 12^{\prime} 0 \mathrm{~W}$ e altitude de 547 metros. Em ambiente externo foi retirada uma camada de tecido superficial e posteriormente, no laboratório, as mudas foram reduzidas a blocos com aproximadamente $25 \mathrm{~mm}^{3}$ de rizoma x $35 \mathrm{~mm}$ de altura do pseudocaule contendo os meristemas apicais. Em condições assépticas, os blocos foram descontaminados em $500 \mathrm{~mL}$ de solução de hipoclorito de sódio comercial a $50 \%$, contendo $1 \%$ de cloro ativo, com cinco gotas de Tween 80 , por $30 \mathrm{~min}$. Foram realizadas três lavagens em água deionizada estéril e os explantes ficaram imersos na água da última lavagem. Os ápices caulinares foram reduzidos para, aproximadamente, $15 \mathrm{~mm}$ de pseudocaule e $5 \mathrm{~mm}$ de rizoma, contendo o meristema apical mais algumas camadas de primórdios foliares.

Os ápices caulinares foram estabelecidos no meio MS (MURASHIGE \& SKOOG, 1962), com metade da concentração dos macronutrientes, acrescido de $30 \mathrm{~g} \mathrm{~L}^{-1}$ de sacarose, $1 \mathrm{mg} \mathrm{L}^{-1}$ de BAP (6-benzilaminopurina) e solidificado com $1,6 \mathrm{~g} \mathrm{~L}^{-1}$ de Phytagel $^{\mathrm{TM}}$. $\mathrm{O} \mathrm{pH}$ foi ajustado para 5,8, antes da autoclavagem. Após a inoculação, os ápices caulinares permaneceram em câmara escura por 10 dias e, em seguida, foram levados para a sala de crescimento, sob temperatura de $25 \pm 2{ }^{\circ} \mathrm{C}$, com fotoperíodo de $16 \mathrm{~h}$ de claro e intensidade luminosa de $50 \mu \mathrm{mol} \mathrm{m} \mathrm{m}^{-2} \mathrm{~s}^{-1}$, proporcionada por lâmpadas fluorescentes, tipo luz do dia. Após 30 dias, os ápices caulinares passaram para a fase de multiplicação, sendo realizadas duas repicagens em intervalos de 30 dias, permanecendo por todo o período de multiplicação em presença de luz. Nesta fase, foram cultivados no mesmo meio utilizado para a fase de estabelecimento, mudando-se apenas a concentração de
BAP para $3 \mathrm{mg} \mathrm{L}^{-1}$ e sem a adição de antioxidantes. $\mathrm{Na}$ primeira repicagem procedeu-se à quebra da dominância apical, por meio de um corte longitudinal. Em todas as fases, os ápices caulinares foram cultivados individualmente em frascos de $250 \mathrm{~mL}$, contendo $50 \mathrm{~mL}$ de meio de cultivo.

Para composição dos tratamentos foi utilizada a combinação de $0,25 \mathrm{~g} \mathrm{~L}^{-1}$ de ácido cítrico e $0,75 \mathrm{~g} \mathrm{~L}^{-1} \mathrm{de}$ citrato de potássio em imersão (pré-tratamento) dos ápices caulinares por 90 minutos e em adição ao meio de estabelecimento. Tanto a solução para pré-tratamento, como o meio contendo os antioxidantes foram autoclavados. Também foi realizada a transferência dos ápices caulinares para um novo local do frasco aos 15 dias, evitando o alo de fenol que se formou. Os tratamentos avaliados foram: Pré-tratamento com antioxidantes, cultivo no meio sem antioxidantes, sem transferência dos ápices caulinares aos 15 dias; Pré-tratamento com antioxidantes, cultivo no meio sem antioxidantes, com transferência dos ápices caulinares aos 15 dias; Pré-tratamento com antioxidantes, cultivo no meio com antioxidantes, sem transferência dos ápices caulinares aos 15 dias; Prétratamento com antioxidantes, cultivo no meio com antioxidantes, com transferência dos ápices caulinares aos 15 dias; Sem pré-tratamento com antioxidantes, cultivo no meio sem antioxidantes, sem transferência dos ápices caulinares aos 15 dias; Sem pré-tratamento com antioxidantes, cultivo no meio sem antioxidantes, com transferência dos ápices caulinares aos 15 dias; Sem prétratamento com antioxidantes, cultivo no meio com antioxidantes, sem transferência dos ápices caulinares aos 15 dias; Sem pré-tratamento com antioxidantes, cultivo no meio com antioxidantes, com transferência dos ápices caulinares aos 15 dias.

Segundo metodologia adaptada de Silva et al. (2001), foi realizada uma avaliação visual da oxidação na fase de estabelecimento dos explantes. A avaliação foi realizada por escala de notas, gerando um índice de oxidação, sendo 1 = sem oxidação, 2 = pouco oxidado, $3=$ medianamente oxidado, 4 = muito oxidado. Também foram avaliados o número de brotos no primeiro e no segundo repiques, na fase de multiplicação.

Cada tratamento foi constituído por 15 ápices caulinares e o delineamento utilizado foi o inteiramente casualizado, sendo que cada frasco, contendo um ápice caulinar, correspondeu a uma repetição. Os dados de grau de oxidação e de número de brotações na primeira e segunda repicagem foram submetidos à análise de variância, em esquema fatorial $2 \times 2 \times 2$ e teste de médias de Tukey $(\mathrm{p}<0,05)$. Para análise do número de brotos na 
primeira e segunda repicagem os dados foram transformados para $\sqrt{x+1}$.

Para o grau de oxidação, a análise de variância mostrou efeito significativo do pré-tratamento, independente da adição de antioxidantes ao meio e da transferência dos ápices caulinares aos 15 dias e também mostrou efeito significativo da interação entre a adição de antioxidantes ao meio com a transferência dos ápices caulinares aos 15 dias. As demais interações não foram significativas. O prétratamento diminuiu a oxidação de ápices caulinares de bananeira (Tabela 1) e é recomendado por Anthony et al. (2004) e Grattapaglia \& Machado (1998). Confirmando os resultados obtidos nesse trabalho, foi verificado que para Symonanthus bancroftii (PANAIA et al., 2001) e Conostephium pendulum (ANTHONY et al., 2004), a combinação de $0,25 \mathrm{~g} \mathrm{~L}^{-1}$ de ácido cítrico mais $0,75 \mathrm{~g} \mathrm{~L}^{-1} \mathrm{de}$ citrato de potássio utilizada em pré-tratamento e adicionada ao meio de cultivo, reduziu a necrose dos tecidos excisados, além de prevenir a oxidação.

TABELA 1 - Oxidação expressa em notas para o prétratamento em solução de antioxidantes em ápices caulinares de bananeira 'Maçã', após 30 dias de cultivo (média de 15 repetições).

\begin{tabular}{ll}
\hline Tratamentos & Notas \\
\hline Sem pré-tratamento com antioxidantes & $1,78 \mathrm{~b}$ \\
Com pré-tratamento com antioxidantes & $0,84 \mathrm{a}$ \\
$\mathrm{CV}(\%)$ & 31,84 \\
\hline
\end{tabular}

Médias seguidas pelas mesmas letras na coluna não diferem entre si pelo teste de Tukey $(\mathrm{p}<0,05)$.

Notas: 1 = sem oxidação, 2 = pouco oxidado, $3=$ medianamente oxidado, 4 = muito oxidado.
Outros antioxidantes foram testados em prétratamento de ápices caulinares de bananeira sendo que Jarret et al. (1985), realizando uma rápida imersão dos ápices caulinares em solução de $50 \mathrm{mg} \mathrm{L}^{-1}$ de cisteína, antes da inoculação no meio de cultivo, também observou redução do escurecimento dos ápices caulinares e da coloração do meio de cultivo.

Para a interação entre a transferência dos ápices caulinares aos 15 dias e a adição de antioxidantes (Tabela 2), foi observado que a adição de antioxidantes foi prejudicial, aumentando a oxidação para os dois níveis de transferência. Porém, a transferência dos ápices caulinares aos 15 dias se faz necessária somente se houver a adição de antioxidantes ao meio, pois, nesse caso, há redução do grau de oxidação dos explantes em relação ao não transferido.

Assim, o efeito benéfico do pré-tratamento dos antioxidantes testados (Tabela 1), não se repetiu quando os antioxidantes foram acrescentados ao meio de cultivo, ocasião em que as substâncias tiveram o efeito contrário ao esperado com aumento da oxidação (Tabela 2). Este efeito somente foi reduzido quando os ápices caulinares foram transferidos para um novo local do meio.

Outros autores também observaram a ineficiência da adição de antioxidantes ao meio de cultivo. Silva et al. (2001), testando várias formas de utilização de antioxidantes no processo de micropropagação de bananeira 'Pioneira' (Grupo AAAB), observaram que adição de $10 \mathrm{mg} \mathrm{L}^{-1}$ de ácido ascórbico, no estabelecimento dos explantes e até o sexto subcultivo, ou a adição de $50 \mathrm{ml} \mathrm{L}^{-1}$ de caseína hidrolizada até o sexto subcultivo não promoveram efeito significativo na redução do processo de oxidação e, portanto, não foram recomendados para a micropropagação em escala

TABELA 2 - Oxidação expressa em notas, para a interação entre a transferência dos ápices caulinares aos 15 dias e a adição de $0,25 \mathrm{~g} \mathrm{~L}^{-1}$ de ácido cítrico e $0,75 \mathrm{~g} \mathrm{~L}^{-1}$ de citrato de potássio em meio de cultivo em ápices caulinares de bananeira 'Maçã', após 30 dias de cultivo (média de 15 repetições).

\begin{tabular}{lcc}
\hline Transferência dos ápices caulinares & \multicolumn{2}{c}{ Adição de antioxidantes ao meio de cultivo } \\
\cline { 2 - 3 } aos 15 dias & Sem antioxidantes & Com antioxidantes \\
\hline & & Notas \\
\hline Sem transferência & 0,83 a A & $2,19 \mathrm{~b} \mathrm{~B}$ \\
Com transferência & 0,71 a A & 1,39 a B \\
\hline
\end{tabular}

Médias seguidas pelas mesmas letras minúsculas nas colunas e maiúsculas nas linhas não diferem entre si pelo teste de Tukey $(\mathrm{p}<0,05)$.

Notas: 1 = sem oxidação, 2 = pouco oxidado, 3 = medianamente oxidado, 4 = muito oxidado. 
comercial. Utino et al. (2001), avaliando a adição de $25 \mathrm{mg} \mathrm{L}^{-1}$ de ácido ascórbico ao meio de cultivo e a freqüência de subcultivos na micropropagação de bananeira 'Prata' (Grupo AAB), observaram que, na presença de ácido ascórbico, a oxidação foi semelhante para os subcultivos a cada 7 e 14 dias, porém, quando não se adicionou este antioxidante ao meio de cultura, a oxidação foi significativamente maior para o subcultivo a cada 28 dias. Alloufa et al. (2002) adicionaram ao meio de cultivo $1 \mathrm{~g} \mathrm{~L}^{-1}$ de carvão ativo ou $125 \mathrm{mg} \mathrm{L}^{-1}$ de cisteína no estabelecimento in vitro de inflorescências de bananeira 'Pacovan' (Grupo AAB) e observaram que os níveis de oxidação permaneceram elevados, independentemente da utilização dos antioxidantes.

Não foram observadas diferenças significativas para número total de brotos na primeira repicagem entre os tratamentos realizados. Sendo a média geral de 1,41 brotos por explante. Oliveira et al. (2001), buscando desenvolver um procedimento eficiente para a produção de mudas de bananeiras tetraplóides, utilizaram 7 clones de 'FHIA-01' e observaram que a oxidação é maior na fase de estabelecimento dos explantes, no primeiro repique e nas fases iniciais dos demais repiques, não comprometendo a multiplicação de bananeiras tetraploides, obtendo médias de 1,71 e 2,87 brotos para o primeiro e segundo repiques, respectivamente.

Para número total de brotos na segunda repicagem (Tabela 3) observou-se efeito significativo somente para a adição de antioxidantes ao meio de cultivo. Houve aumento do número de brotos quando os antioxidantes não foram adicionados ao meio de cultivo, confirmando que a diminuição da oxidação, na fase de estabelecimento, promove aumento do número de brotos, fato este observado na Tabela 2. Lameira et al. (1990), estudando um meio de cultivo apropriado para multiplicação e enraizamento de bananeira 'Prata', concluíram que a ocorrência de oxidação fenólica foi prejudicial para o desenvolvimento inicial de brotos, obtendo médias próximas a 2,5 brotos no primeiro e segundo repiques, para uma concentração de BAP próxima à utilizada neste trabalho.

O pré-tratamento dos ápices caulinares em solução de $0,25 \mathrm{~g} \mathrm{~L}^{-1}$ de ácido cítrico e $0,75 \mathrm{~g} \mathrm{~L}^{-1}$ de citrato de potássio, por 90 minutos, tem efeito antioxidante em prétratamento dos ápices caulinares de bananeira 'Maçã'. A adição dos antioxidantes ao meio de cultivo aumenta a oxidação e causa diminuição do número de brotos nas primeiras repicagens .
TABELA 3 - Número de brotos na segunda repicagem, para a adição de $0,25 \mathrm{~g} \mathrm{~L}^{-1}$ de ácido cítrico e $0,75 \mathrm{~g} \mathrm{~L}^{-1} \mathrm{de}$ citrato de potássio em meio de cultivo em ápices caulinares de bananeira 'Maçã', após 60 dias de cultivo (média de 15 repetições).

\begin{tabular}{lc}
\hline $\begin{array}{l}\text { Adição de antioxidantes ao meio de } \\
\text { cultivo }\end{array}$ & $\begin{array}{c}\text { Número de } \\
\text { brotos }\end{array}$ \\
\hline Sem adição de antioxidantes & $3,78 \mathrm{~b}$ \\
Com adição de antioxidantes & $3,20 \mathrm{a}$ \\
\hline Média Geral & 3,50 \\
CV $(\%)$ & 17,68 \\
\hline
\end{tabular}

Médias seguidas pelas mesmas letras na coluna não diferem entre si pelo teste de Tukey $(\mathrm{p}<0,05)$.

\section{AGRADECIMENTOS}

À COOPABAN - Cooperativa Palmitalense dos Bananicultores pelo fornecimento das mudas e à ADRBIOMAVALE - Sociedade Civil de Interesse Público pela cessão do "Laboratório de Cultivo in vitro" para realização deste trabalho.

\section{REFERÊNCIAS BIBLIOGRÁFICAS}

ALlOUFA, M. A. I.; MACÊDO, C. E. C.; BARROSO, P. A. V.; BARBALHO, A. D.; OLIVEIRA, C. H. B. Avaliação de dois agentes antioxidantes no estabelecimento in vitro de inflorescências de bananeira ( $M u s a s p p)$. Ciência e Agrotecnologia, Lavras, v. 26, n. 5, p. 1092-1096, set./out. 2001.

ANTHONY, J. M.; SENARATNA, T.; DIXON, K. W.; SIVASITHAMPARAM, K. The role of antioxidants for initiation of somatic embryos with Conostephium pendulum Benth. (Ericaceae). Plant Cell, Tissue and Organ Culture, Netherlands, v. 78, n. 3, p. 247-252, set. 2004.

GRATTAPAGLIA, D.; MACHADO, M. A. Micropropagação. In: TORRES, A. C.; CALDAS, L. S.; BUSO, J. A. Cultura de tecidos e transformação genética de plantas. Brasília, DF: Embrapa-SPI, 1998. v. 1, p. 183-260.

JARRET, R. L.; RODRIGUEZ, W.; FERNANDEZ, R. Evaluation, tissue culture propagation, and dissemination of 'Saba' and 'Pelipita' plantains in Costa Rica. Scientia Horticulturae, Amsterdam, v. 25, p. 137-147, set./out. 1985. 
LAMEIRA, O. A.; PINTO, J. E. B. P.; PASQUAL, M. Propagação in vitro da bananeira 'Prata' através da cultura de tecidos. Revista Brasileira de Fruticultura, Brasília, v. 25, n. 11, p. 1613-1617, nov. 1990.

MURASHIGE, T.; SKOOG, F. A revised medium for rapid growth and bioassays with tobacco tissue cultures. Physiology Plantarum, Copenhagen, v. 15, p. 473-479, June 1962.

OLIVEIRA, R. P.; SILVEIRA, D. G.; SILVA, S. O. S. Concentração de BAP e a eficiência de micropropagação de bananeira tetraplóide (Grupo AAAB). Revista Brasileira de Fruticultura, Cruz das Almas, v. 23, n. 2, p. 409-412, jan./mar. 2001.

PANAIA, M.; SENARATNA, T.; BUNN, E.; DIXON, K. W.; SIVASITHAMPARAM, K. Micropropagation of the critically endangered Western Australian species, Symonanthus bancroftii (F. Muell.) L. Haegi (Solanaceae). Plant Cell, Tissue and Organ Culture, Netherlands, v. 63, n. 1, p. 23-29, jan. 2000.

SILVA, K. M.; OLIVEIRA, R. P.; ARAÚJO, F. P.; SILVA, V. C. Utilização de antioxidantes na micropropagação de bananeira cv. Pioneira. Magistra, Cruz das Almas, v. 13, n. 1, p. 5-8, jan./jun. 2001.
SOUZA, A. S.; CORDEIRO, Z. J. M.; TRINDADE, A. V. Produção de mudas. In: CORDEIRO, Z. J. M. Banana: produção. Brasília, DF: Embrapa Comunicação para Transferência de Tecnologia, 2000. p. 39-46.

SOUZA, A. S.; DANTAS, J. L. L.; SOUZA, F. V. D.; CORDEIRO, Z. J. M.; SILVA NETO, S. P. Propagação. In: ALVES, E. J. A Cultura da banana: aspectos técnicos, socioeconômicos e agroindustriais. 2. ed. Brasília, DF: Embrapa-SPI, 1999. p. 151-195.

UTINO, S.; CARNEIRO, I. F.; CHAVES, L. J. Crescimento e oxidação de explantes de bananeira prata (Musa AAB) in vitro: IV. concentrações de sais, ácidos ascórbicos e freqüência de subcultivos. Revista Brasileira de Fruticultura, Cruz das Almas, v. 23, n. 2, p. 409-412, ago. 2001.

VUYLSTEKE, D.; LANGHE, E. de. Feasibility of in vitro propagation of bananas and plantains. Tropical Agriculture, Trinidad, v. 62, n. 4, p. 323-328, out. 1985.

ZAFFARI, G. R.; SOLIMAN FILHO, L. F.; STUKER, H. Efeito do tamanho do explante e da quebra de dominância apical sobre a brotação das gemas laterais na produção de mudas de bananeira in vitro. Revista Brasileira de Fruticultura, Cruz das Almas, v. 16, n. 3, p. 71-76, dez. 1994. 